\title{
Stroke prevention in older adults with atrial fibrillation
}

\author{
Michiel Coppens MD PhD, Robert G. Hart MD, John W. Eikelboom MBBS
}

See related research article by $\mathrm{Xu}$ and colleagues in CMAJ Open at www.cmajopen.ca/content/1/3/E115

$\mathrm{T}$ he new oral anticoagulants dabigatran, rivaroxaban and apixaban are approved in more than 80 countries for stroke prevention in patients with atrial fibrillation. These medications offer simplification of long-term oral anticoagulation because, unlike vitamin $\mathrm{K}$ antagonists, they do not require routine coagulation monitoring or dietary restrictions. Moreover, in phase III trials of their use in atrial fibrillation, the new oral anticoagulants reduced the risk of intracranial bleeding by 30\%-70\% compared with warfarin and were at least as effective as warfarin in preventing ischemic stroke. ${ }^{1}$ On the basis of these findings, guidelines recommend new oral anticoagulants in preference to vitamin $\mathrm{K}$ antagonists in most patients with atrial fibrillation. ${ }^{2,3}$

In an article published in CMAJ Open, $\mathrm{Xu}$ and colleagues present an evaluation of prescribing patterns of oral anticoagulants in the province of Ontario, Canada, since the approval of dabigatran, the first new oral anticoagulant to become available in Canada for stroke prevention in atrial fibrillation. ${ }^{4}$ Over the 24-month study period from October 2010 to September 2012, prescriptions for new oral anticoagulants in the province rose steadily, with a corresponding decline in prescriptions for warfarin. By the end of the study period, new oral anticoagulants represented $21 \%$ of all prescriptions for oral anticoagulants. Age-specific prescribing rates of dabigatran were highest among older patients, and more than $90 \%$ of prescriptions for dabigatran among patients 85 years or older were for the lower dosage (110 mg twice daily).

$\mathrm{Xu}$ and colleagues are concerned that older patients were not adequately represented in the randomized controlled trials of new oral anticoagulants for stroke prevention in atrial fibrillation and conclude that there is an urgent need to evaluate outcomes in clinical practice. ${ }^{4}$ Are their concerns justified?

Population data indicate that atrial fibrillation affects $1 \%-2 \%$ of the general population and that the prevalence of atrial fibrillation and burden of related stroke rise sharply with age. ${ }^{5}$ The median age of patients with atrial fibrillation is 75 years, and the condition affects $10 \%$ of patients over the age of $80 .{ }^{5}$ One-sixth of all strokes are cardio- embolic, a rate that rises to almost one-third among patients over $80 .{ }^{5}$ Strokes in patients with atrial fibrillation are associated with greater morbidity and mortality than strokes in those without atrial fibrillation. Nevertheless, vitamin K antagonists are consistently underused in older patients, with the most common barriers being concerns about inconvenience and risk of bleeding. ${ }^{6}$

The simplicity of treatment with new oral anticoagulants makes them particularly attractive as an alternative to warfarin in older patients, but do the efficacy and safety results from randomized controlled trials of new oral anticoagulants also apply to older patients in clinical practice?

Three completed phase III trials compared a new oral anticoagulant with warfarin in patients with atrial fibrillation. These randomized controlled trials collectively included 19100 patients with atrial fibrillation who were 75 years or older, which is more than the total number of patients included in prior trials comparing warfarin with placebo or untreated control $(n=2900)$ or comparing warfarin with acetylsalicylic acid $(n=$ 4620). ${ }^{1,7}$ Although the absolute risk of stroke and bleeding is substantially higher among older patients than among younger patients, the relative effects of new oral anticoagulants compared with

\section{- KeY POINTS}

- Older patients with atrial fibrillation have a higher risk of stroke and worse outcomes after stroke than younger patients, but many do not receive recommended anticoagulation treatment.

- Subgroup analyses of data for more than 19100 patients aged 75 years or older enrolled in phase III trials suggest that the new oral anticoagulants dabigatran, rivaroxaban and apixaban offer consistent benefits over warfarin in older patients with atrial fibrillation.

- The rate of intracranial bleeding, the most feared complication of anticoagulation, is related to age and is sharply reduced by the new anticoagulants relative to warfarin, making these agents particularly attractive for older patients.

- Uptake of new oral anticoagulants in Canada has been rapid. Their use in older patients is consistent with guideline recommendations and is supported by the results of clinical trials.

- Ongoing surveillance by regulatory authorities and postmarketing studies of the use of new oral anticoagulants will help to inform uptake of the medications and related outcomes among older patients in clinical settings. 
control were consistent for the primary efficacy outcome of stroke or systemic embolism in all 3 trials and for major bleeding in the ROCKET-AF and ARISTOTLE trials. ${ }^{1}$

A significant interaction between age and treatment was evident for major bleeding in the RE-LY trial. Among patients 75 years or older $(n=7258)$, $150 \mathrm{mg}$ of dabigatran twice daily was associated with a borderline significant increase in major bleeding, and $110 \mathrm{mg}$ twice daily with a similar rate of major bleeding, compared with warfarin. Among patients less than 75 years of age, both doses were associated with a reduction in major bleeding. ${ }^{1}$ The increase in major bleeding with the higher dose of dabigatran in the older patients was confined to extracranial bleeding; both doses of dabigatran were associated with lower rates of intracranial bleeding irrespective of age. Furthermore, the results obtained with dabigatran for both total stroke and intracranial bleeding were consistent among patients 80 years or older $(n=3016)$ and those 85 or older $(n=720){ }^{8}$ These findings would appear to support recommendations by Canadian, European and Australian regulators for preferential use of the lower dose of dabigatran in patients 75 years or older. Regulators in the United States did not approve the lower dosage of $110 \mathrm{mg}$ twice daily, reasoning that there was no population (including older patients) for whom the availability of a lower dose would improve dabigatran's benefit-risk profile.

A postmarketing report from the US Food and Drug Administration and the results of a Danish nationwide study provide additional reassurance about the safety of new oral anticoagulants in the general population..$^{910}$ Both reports are subject to confounding because of their observational design, but they provide no evidence that bleeding rates experienced to date with dabigatran are any higher in the real world than those reported in the randomized controlled trials.

Guideline panels have long highlighted the underuse of anticoagulants for stroke prevention in patients with atrial fibrillation. Regulatory approval of 3 new oral anticoagulants holds the promise that a greater proportion of patients with atrial fibrillation at risk for stroke will receive effective preventive therapy. We believe that the findings of $\mathrm{Xu}$ and colleagues of increasing use of new oral anticoagulants among Canadians with atrial fibrillation are encouraging and that the pattern of uptake of these agents is supported by the data from the randomized trials. We agree, however, that there is no room for complacency, because anticoagulants can cause serious bleeding and the risk of complications is increased when new oral anticoagulants are not used according to approved indications. Translation of the favourable results of the trials into benefits for patients requires clinicians to prescribe new oral anticoagulants for the right patient and at the right dose, with appropriate follow-up and periodic monitoring of renal function (e.g., at least once per year and more often in the presence of moderate impairment).

Ongoing surveillance by regulatory agencies and evidence from large-scale international postmarketing studies such as GLORIA-AF (www.gloria-af.com) and GARFIELD (www.trilondon.ac.uk/garfield) should help to inform the future uptake of new oral anticoagulants and related outcomes in real world settings.

\section{References}

1. Barco S, Cheung YW, Eikelboom JW, et al. New oral anticoagulants in elderly patients. Best Pract Res Clin Haematol 2013;26: 215-24.

2. Camm AJ, Lip GY, De Caterina R, et al. 2012 focused update of the ESC guidelines for the management of atrial fibrillation: an update of the 2010 ESC guidelines for the management of atrial fibrillation. Developed with the special contribution of the European Heart Rhythm Association. Eur Heart J 2012;33:2719-47.

3. Skanes AC, Healey JS, Cairns JA, et al. Focused 2012 update of the Canadian Cardiovascular Society atrial fibrillation guidelines: recommendations for stroke prevention and rate/rhythm control. Can J Cardiol 2012;28:125-36.

4. Xu Y, Holbrook AM, Simpson CS, et al. Prescribing patterns of novel oral anticoagulants following regulatory approval for atrial fibrillation in Ontario, Canada: a population-based descriptive analysis. CMAJ Open 2013;1;E115-9.

5. Wolf PA, Abbott RD, Kannel WB. Atrial fibrillation as an independent risk factor for stroke: the Framingham Study. Stroke 1991;22:983-8.

6. Nieuwlaat R, Capucci A, Lip GY, et al. Antithrombotic treatment in real-life atrial fibrillation patients: a report from the Euro Heart Survey on Atrial Fibrillation. Eur Heart J 2006;27:3018-26.

7. Hart RG, Pearce LA, Aguilar MI. Meta-analysis: antithrombotic therapy to prevent stroke in patients who have nonvalvular atrial fibrillation. Ann Intern Med 2007;146:857-67.

8. Pradaxa [product monograph]. Burington $(\mathrm{ON})$ : Boehringer Ingelheim Canada Ltd.; 2013. Available: www.boehringer-ingelheim.ca/content/dam/internet/opu/ca_EN/documents/humanhealth/product_monograph/PradaxaPMEN0513.pdf (accessed 2013 Sept. 19).

9. Larsen TB, Rasmussen LH, Skjoth F, et al. Efficacy and safety of dabigatran etexilate and warfarin in "real-world" patients with atrial fibrillation: a prospective nationwide cohort study. J Am Coll Cardiol 2013;61:2264-73.

10. Southworth MR, Reichman ME, Unger EF. Dabigatran and postmarketing reports of bleeding. N Engl J Med 2013;368:1272-4.

Competing interests: Michiel Coppens has received a research grant, travel support and lecturing fees from Boehringer-Ingelheim and lecturing fees from Bayer; both are manufacturers of a new oral anticoagulant. John Eikelboom has served on committees for the RE-LY, ROCKET-AF and AVERROES studies and has received honoraria and research support from companies that market new oral anticoagulants, including Bayer, Boehringer-Ingelheim, Bristol-Myers Squibb, Janssen and Pfizer; he also works in an anticoagulation clinic that manages more than 2000 patients with warfarin. No competing interests were declared by Robert Hart.

Affiliations: Department of Vascular Medicine (Coppens), Academic Medical Center, Amsterdam, The Netherlands; Population Health Research Institute (Coppens, Hart, Eikelboom), Hamilton, Ont.; Department of Medicine (Hart, Eikelboom), McMaster University, Hamilton, Ont.

Contributors: Michiel Coppens prepared the first draft of the commentary, and Robert Hart and John Eikelboom revised subsequent versions for intellectual content. All the authors approved the final version submitted for publication. 